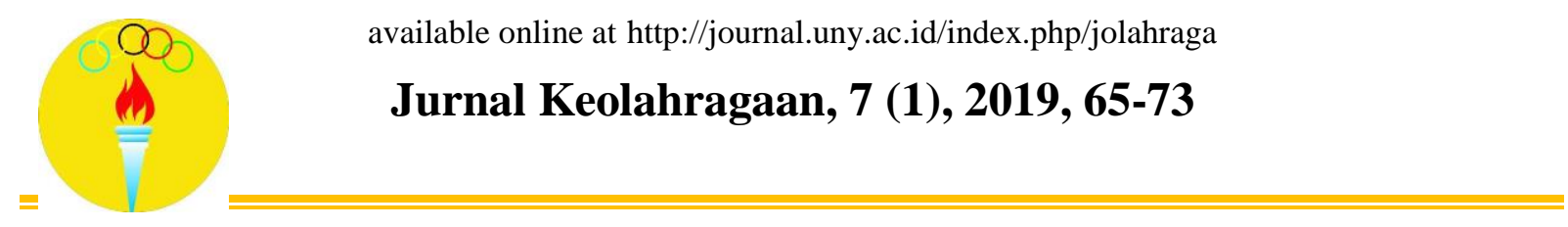

\title{
Pengaruh pemberian jus mentimun dan minuman isotonik terhadap tingkat dehidrasi pada latihan Zumba fitness
}

\author{
Rizki Yudha Pratama *, Imas Damayanti, Yati Ruhayati \\ Program Studi Ilmu Keolahragaan, Fakultas Pendidikan Olahraga dan Kesehatan, Universitas \\ Pendidikan Indonesia. Jl. DR. Setiabudi No.229, Bandung, Jawa Barat 40154, Indonesia \\ * Corresponding Author. E-mail: rizkiyp7@ student.upi.edu
}

Received: 25 May 2019; Revised: 29 July 2019; Accepted: 1 August 2019

\begin{abstract}
Abstrak
Penelitian ini bertujuan untuk mengetahui pengaruh pemberian jus mentimun dan minuman isotonik terhadap tingkat dehidrasi. Metode yang digunakan yaitu dengan eksperimen dengan desain penelitian cross over design. 8 orang mahasiswa keperawatan UPI 2018 berpartisipasi sebagai sampel dalam penelitian ini. Dehydrating exercise test yang digunakan dalam penelitian ini adalah Zumba fitness selama 60 menit. Instrumen pengambilan data menggunakan Urine Refractometer Spesific Gravity dan 5 visual analog scale. Hasil dari penelitian ini menunjukkan bahwa tidak terdapat perbedaan yang signifikan antara hasil pre-test dan post-test pada jus mentimun dan minuman isotonik terhadap tingkat dehidrasi sebesar $\mathrm{p}(0.83)$ dan $\mathrm{p}(1.52)$. Pada penilaian subjektif tidak terdapat perbedaan yang signifikan pada penilaian subjektif antara jus mentimun dan minuman isotonik dengan nilai signifikansi sebesar Thirst $\mathrm{p}(0.398)$, Bloatedness $\mathrm{p}(0.609)$, Refreshed $\mathrm{p}(0.758)$, Stomach upset $\mathrm{p}(0.486)$ dan Tiredness $(0.683)$. Demikian pula tidak terdapat perbedaan yang signifikan antara jus mentimun dan minuman isotonik terhadap tingkat dehidrasi dengan taraf signifikansi sebesar $\mathrm{p}(0.696)$. Hal ini menunjukkan bahwa jus mentimun dapat mengurangi potensi terjadinya dehidrasi sama baiknya dengan minuman isotonik. Ini membuktikan bahwa jus mentimun dapat menggantikan minuman isotonik sebagai minuman olahraga
\end{abstract}

Kata Kunci: dehidrasi, mentimun, minuman isotonik, Zumba fitness

\section{The effect of giving cucumber juice and isotonic drink of dehydration level on Zumba fitness exercise}

\begin{abstract}
This research is intended to know comparison the effect of giving cucumber juice and isotonic drink on level of dehydration. Method which is used is experiment with cross over design. 8 UPI 2018 nursing students participated as samples in this research. Dehydrating exercise test that used in this research is Zumba fitness for 60 minute. Instrument data retrieval uses Urine Refractometer Spesific Gravity dan 5 visual analog scale. The result of this research indicated that there's no difference significantly between the results of pre-test and post-test on cucumber juice and isotonic drink to the level of dehydration $p(0.83)$ and $p(1.52)$. In subjective assessment there is no significant difference in the subjective assessment between cucumber juice and isotonic drink with a significance in the amount of Thirst $p(0.398)$, Bloatedness $p(0.609)$, Refreshed $p(0.758)$, Stomach upset $p(0.486)$ dan Tiredness $p(0.683)$. As well as there is no significant difference between cucumber juice and isotonic drink to the level of dehydration with a significance level of $p(0.696)$. This shows that cucumber juice can reduce the potential of dehydration as good as isotonic water. It proved that cucumber juice can replaced isotonic water as sport drink.
\end{abstract}

Keywords: dehydration, cucumber, isotonic drink, Zumba fitness

How to Cite: Pratama, R., Damayanti, I., \& Ruhayati, Y. (2019). Pengaruh pemberian jus mentimun dan minuman isotonik terhadap tingkat dehidrasi pada latihan Zumba fitness. Jurnal Keolahragaan, 7(1), 65-73. doi:https://doi.org/10.21831/jk.v7i1.25126

doi) https://doi.org/10.21831/jk.v7i1.25126

\section{PENDAHULUAN}

Di dalam olahraga terdapat beberapa faktor yang mempengaruhi prestasi atlet,salah satu- nya berkaitan dengan gizi. Salah satu unsur gizi yang harus dipenuhi atlet adalah air. Menurut Galemore (2011), air adalah bagian penting dari kebutuhan sehari-hari. Hidrasi yang sesuai diper- 
lukan untuk menjaga kerja jantung tetap normal, suhu tubuh, dan banyak fungsi fisiologis lain selama latihan dan aktivitas rutin sehari-hari. Kekurangan konsumsi cairan dapat menyebabkan dehidrasi,kelelahan,dan penurutan performa atlet. Dehidrasi adalah kondisi tidak diinginkan karena ada ketidak seimbangan pada fungsi homeostatis, tidak hanya pada usia renta, yaitu anak anak dan lansia tapi juga pada remaja (Adan \& Adan, 2012). Murray (2007) mengungkapkan bahwa penurunan air dalam tubuh dari kadar normal (sering disebut dehydrasi atau hypohydrasi) memicu perubahan pada fungsi kardiovaskular, thermoleguratoy, metabolisme, dan saraf pusat yang akan semakin buruk seiring dengan memburuknya tingkat dehidrasi.

Baru-baru ini, salah satu olahraga terpopuler yang ada di kelas-kelas fitness adalah kelas Zumba. Zumba pertama kali ditemukan pada pertengahan tahun 1990 oleh seorang fitness trainer, Alberto "Beto" Perez. Salah satu alasan mengapa Zumba populer adalah penemu dari Zumba mengeklaim bahwa tidak ada benar dan salah saat melakukan gerakan Zumba, partisipan dapat bebas bergerak mengikuti irama lagu dan koreografinya jauh lebih tidak formal daripada kelas-kelas latihan lainnya. Zumba diasumsikan dapat membuat dehidrasi karena menurut Luettgen et al. (2012) selama 39 menit dapat membakar kalori sekitar 369 kalori atau sekitar 9,5 kkal per menit.

Untuk menjaga tubuh agar tetap terhidrasi maka diperlukan pemberian cairan dan karbohidrat yang tepat. Hal ini diperkuat oleh Irawan (2007) yang mengemukakan bahwa untuk menghambat terjadinya kelelahan terutama bagi atlet endurance (daya tahan) serta untuk menjaga konsentrasi glukosa darah,jumlah ideal konsumsi karbohidrat yang disarankan pada saat berolahraga adalah 30-60 gram/jam. Pada saat olahraga tubuh juga akan membutuhkan cairan agar terhindar dari kekurangan cairan, maka kebutuhan karbohidrat ini juga dapat dipenuhi melalui konsumsi $600-1.500 \mathrm{ml}$ air putih yang ditambahkan 24-100 gr karbohidrat (4-7\% larutan karbohidrat) tiap jamnya. Salah satu minuman yang dapat dijadikan pilihan untuk mengatasi dehidrasi adalah minuman isotonik. Air digunakan untuk mengganti cairan tubuh, karbohidrat yang digunakan sebagai penyuplai energi, dan mineral untuk menggantikan elektrolit tubuh yang hilang adalah komponen utama dari minuman isotonik. (Koswara, 2009)

Namun terdapat beberapa bahaya dari mengkonsumsi minuman isotonik dalam jangka waktu yang panjang. Galemore (2011) mengemukakan bahwa, minuman olahraga yang mengandung karbohidrat harus dihindari atau dibatasi karena dapat menyebabkan kalori yang berlebihan dan menyebabkan peningkatan resiko kelebihan berat badan dan obesitas serta kerusakan gigi. Selain minuman isotonik, jus buah juga dapat membantu mengatasi dehidrasi. Menurut Rani et al. (2014) mentimun mempunyai elektrolit yang penting dan dapat mengembalikan tingkat hidrasi. Mentimun juga mengandung kadar air yang sangat banyak sekitar 96\%. Mentimun juga memiliki banyak vitamin dan mineral yang membuatnya menjadi bahan makanan yang sehat.

Selain harganya lebih murah jika dibandingkan dengan minuman isotonik, mentimun juga bisa didapatkan dengan mudah diseluruh daerah di Indonesia. Oleh karena itu, perlu diteliti lebih lanjut mengenai mentimun apakah bisa menggantikan minuman isotonik sebagai minuman olahraga. Sehingga dapat memberikan informasi khususnya pelaku olahraga agar para atlet dapat terhindar dari bahaya dehidrasi dengan cara yang alami,serta dapat mengurangi konsumsi minuman isotonik yang cenderung mengandung zat-zat kimia yang dapat membahayakan atlet itu sendiri.

Berdasarkan uraian pada bagian pendahuluan maka tujuan dari penelitian ini adalah untuk mengetahui gambaran tingkat dehidrasi subjek yang menggunakan air mentimun dan minuman isotonik sebagai minuman olahraga, untuk mengetahui apakah terdapat perbedaan penggunaan air mentimun dan minuman isotonik terhadap tingkat dehidrasi sebagai minuman olahraga, untuk mengetahui apakah terdapat perbedaan pandangan subjektif antara penggunaan air mentimun dan minuman isotonik terhadap tingkat dehidrasi sebagai minuman olahraga.

\section{METODE}

Pada penelitian ini metode yang digunakan adalah metode eksperimen. Desain penelitian yang digunakan yaitu cross-over design. Menurut Turner (2013) sampel dari crossover design diberikan treatment 2 kali atau lebih.

Partisipan yang mengikuti penelitian ini adalah mahasiswa keperawatan 2018 Universitas Pendidika Indonesia (UPI) Bandung. Penelitian ini dilaksanakan di Gedung Fakultas Pendidikan Olahraga dan Kesehatan Universitas Pendidikan Indonesia (FPOK UPI) Lantai 1 Ruangan Laboratorium Kebugaran Gym dan Fitness, Jalan Dr. 
Sethiabudi No.229, Isola, Sukasari, Kota Bandung, Jawa Barat 40152.

Teknik pengambilan sampel yang digunakan adalah purposive sampling, dengan mempertimbangkan bahwa sampel tidak merokok, tidak punya riwayat penyakit jantung, metabolisme, saraf, atau kelainan tulang yang bisa mempengaruhi kemampuan untuk mengikuti penelitian dan tidak memulai mengkonsumsi suplemen saat sedang dilakukan penelitian. Namun mereka diizinkan untuk melanjutkan menggunakan suplemen yang mereka minum rutin sebelum dimulainya penelitian, contohnya multivitamin (Kalman et al., 2012). Sampel juga bersedia menggunakan jus mentimun selama penelitian. Dari kriteria sampel yang telah ditetapkan, terpilih 8 sampel untuk berpartisipasi pada penelitian ini.Instrumen yang digunakan pada penelitian ini adalah untuk mengetahui tingkat dehidrasi. Alat yang dibutuhkan yaitu Dehydrating exercise test (Zumba fitness), semakin banyak energi dan kalori dikeluarkan makan individu akan semakin membutuhkan cairan dan elektrolit. Kehilangan cairan dapat menyebabkan dehidrasi. Selanjutnya adalah lima (5) point visual analog scale, digunakan untuk menilai penilaian subjektif sampel pada minuman yang diminum meliputi thirst, bloatedness, refreshed, stomach upset, dan tiredness. Urine Refractometer Spesific Gravity, handheld manual refractometer adalah cara yang sudah diakui valid dan mudah dilakukan (Minton, 2015). Cara penggunaan refractometer (University of Bristol, 2017) adalah kalibrasikan refractometer dan bersihkan terlebih dahulu prisma dengan tisu dan air, teteskan beberapa tetes aquadest atau larutan $\mathrm{NaCI} 5 \%$ pada bagian prisma lalu tutup dengan penutupnya. Lalu, lihat pada bagian eye piece dan pastikan bahwa garis diantara bagian biru dan putih berada pada 1.000 S.PG. Jika tidak kalibrasikan terlebih dahulu hingga garis tersebut berada pada 1.000. Bersihkan prisma pada refractometer dari sisa aquadest yang tertinggal. Teteskan sampel cairan 1-3 tetes pada pada prisma. Kemudian tutup penutup lalu lihat pada eye piece untuk hasilnya.

Langkah pertama yang dilakukan pada penelitian ini ialah memilih populasi dan sampel. Sebelum melakukan penelitian sampel diminta untuk menandatangani informed concent yaitu lembar persetujuan. Lalu sampel dibagi ke dalam dua kelompok secara acak (randomized). Penelitian ini dibagi menjadi dua periode treatment dan satu periode washout, dimana setiap periode treatment terdapat dua kali pemberian treatment yang sama. Pada periode pertama, kelompok 1 sebagai kelompok treatment 1 diberikan jus mentimun lalu melakukan Zumba fitness dan kelompok 2 sebagai kelompok treatment 2 diberikan minuman isotonik lalu melakukan Zumba fitness. Mentimun (Cucumis Sativus) yang digunakan dalam penelitian ini adalah mentimun biasa ditandai dengan penampilan kulit buah yang tipis, lunak, dan pada saat buah muda berwarna hijau keputih putihan, namun setelah tua menjadi berwarna cokelat. Mentimun biasa merupakan jenis mentimun yang sudah berkembang pesat di berbagai daerah di Indonesia (Amin, 2015). Mentimun tersebut diblender dengan perbandingan $250 \mathrm{ml}$ air dan $100 \mathrm{~g}$ mentimun. Sedangkan minuman isotonik yang digunakan pada penelitian ini adalah Pocari Sweat. Pocari Sweat adalah merk minuman isotonik dan minuman olahraga yang populer di negara asalnya, Jepang. Minuman Pocari di produksi oleh Otsuka Pharmaceutical Co, Ltd. Adapun kandungan yang terdapat dalam minuman isotonik adalah pada Tabel 1.

Tabel 1. Kandungan Minuman Isotonik

\begin{tabular}{ll}
\hline Kalori & $26 \mathrm{Kcal}$ \\
Protein & 0 \\
Lemak & 0 \\
Gula & $6.7 \mathrm{~g}$ \\
Sodium & $49 \mathrm{mg}$ \\
Kalsium & $2 \mathrm{mg}$ \\
Pottasium & $20 \mathrm{mg}$ \\
Magnesium & $0.6 \mathrm{mg}$ \\
\hline
\end{tabular}

Dua jam sebelum melakukan treatment subjek diberikan $500 \mathrm{ml}$ air putih. Hal ini bertujuan untuk mengkondisikan status hidrasi atlet (Dwita et al., 2015). Jus mentimun dikonsumsi 15 menit sebelum melakukan Zumba fitness dan ketika 30 menit melakukan Zumba fitness. Sebelum melakukan Zumba fitness sampel diambil urinnya dan dicek menggunakan urin spesific gravity (refractometer). Sebelum melakukan Zumba fitness selama 60 menit, sampel dipersilahkan untuk melakukan pemanasan. Setelah melakukan Zumba sampel diambil kembali urinenya untuk dicek berat jenis urin menggunakan urine spesific gravity. Pada akhir periode treatment pertama sampel diwawancarai menggunakan 5 point visual analog scale untuk mengetahui penilaian subjektif terhadap minuman tersebut. Setelah periode 1 berakhir, diberlakukan fase wash out selama 2 hari untuk menghindari efek carry out dari periode 1 (Zanzer, 2011). Pada periode kedua, kelompok treatment 1 disilangkan dengan kelompok treatment 2 
Jurnal Keolahragaan 7 (1), 2019 - 68

Rizki Yudha Pratama, Imas Damayanti, Yati Ruhayati

sehingga kelompok treatment 1 diberi minuman isotonik dan kelompok treatment 2 diberi jus mentimun lalu melakukan Zumba fitness. Setelah itu hasil dari berat jenis urin akan dianalisis menggunakan SPSS lalu dapat ditarik kesimpulan.

Pada penelitian ini data dianalis menggunakan paired sample t-test untuk menguji pengaruh tiap variabelnya dan Independent Sample T-Test untuk menguji apakah terdapat perbedaan antara jus mentimun dan minuman isotonik terhadap tingkat dehidrasi. Untuk menguji tingkat dehidrasi subjek terlebih dahulu menggunakan Shapiro wilk dan Levene Test sebagai uji normalitas dan homogenitas.

\section{HASIL DAN PEMBAHASAN}

\section{Hasil}

Temuan Jus Mentimun

Pada Gambar 1, ditampilkan bahwa variabel jus mentimun pre-test dengan standar devisiasi 0,001959 memiliki nilai rata-rata sebesar 1,00888 dengan nilai maksimum sebesar 1,012 dan nilai minimum sebesar 1,006. Variabel jus mentimun post-test dengan standar devisiasi 0,00255 memiliki nilai rata-rata sebesar 1,01025 dengan maksimum nilai sebesar 1,015 dan minimum nilai sebesar 1,007 .

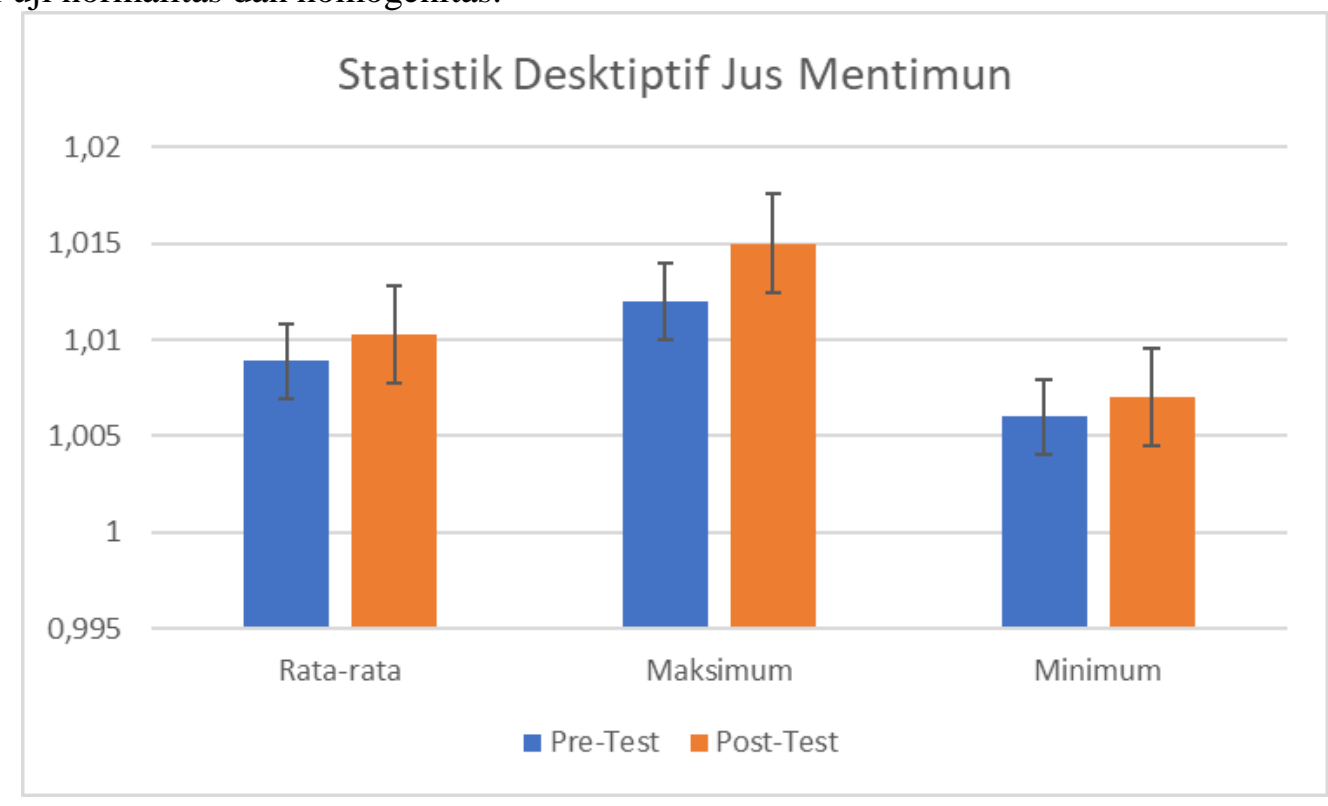

Gambar 1. Statistika Deskriptif Jus Mentimun



Gambar 2. Statistik Deskriptif Isotonik 


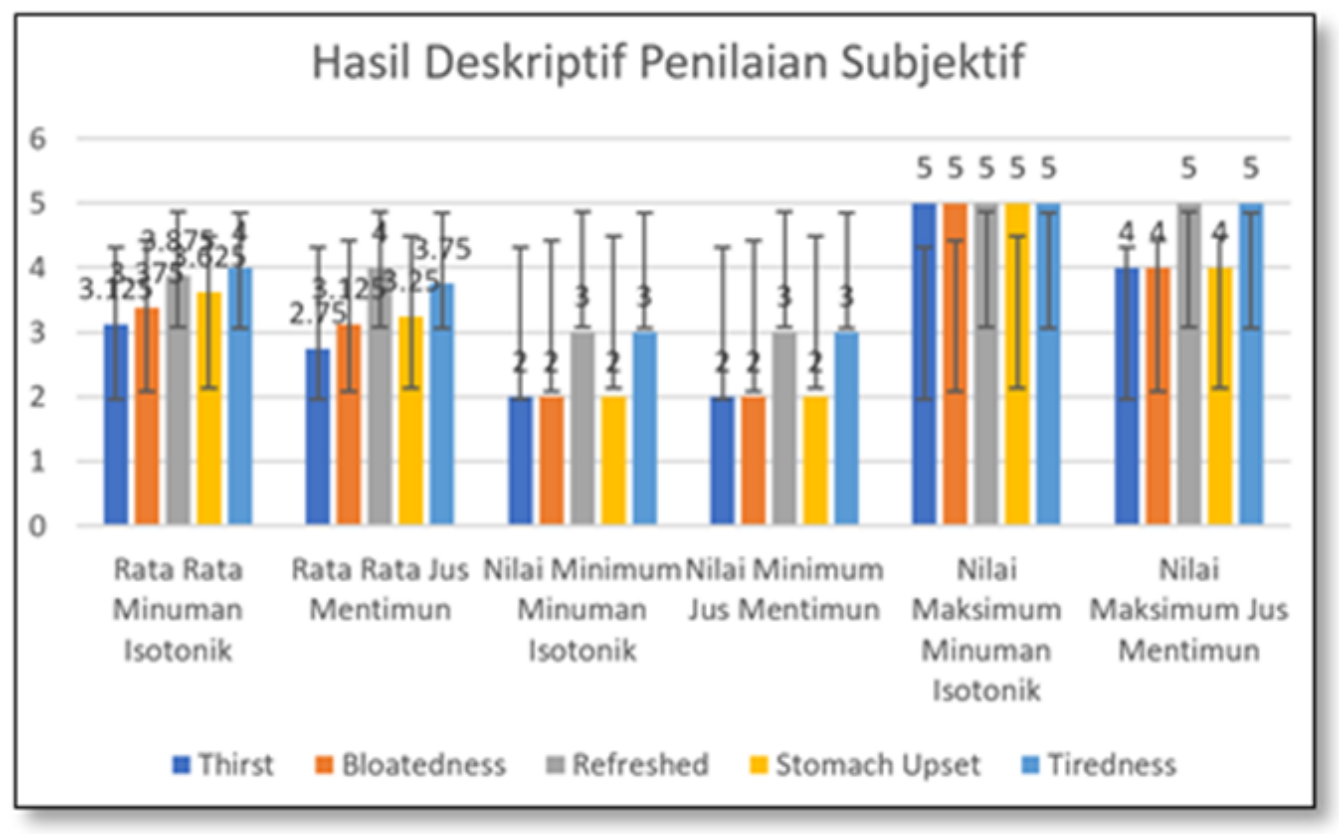

Gambar 3. Statistik Deskriptif Penilaian Subjek

Pada Tabel 2, ditampilkan bahwa BJU jus mentimun pada saat pre-test mempunyai signifikansi sebesar 0,778 dan BJU jus mentimun posttest sebesar 0.695. Nilai signifikansi tersebut lebih dari nilai alpha $(\mathrm{p}>0.05)$. Dapat ditarik kesimpulan bahwa $\mathrm{H} 0$ diterima dan disimpulkan data normal.

Tabel 2. Uji Normalitas Jus Mentimun

\begin{tabular}{lll}
\hline Variabel & N & Sig \\
\hline BJU jus mentimun pre-test & 8 & 0.778 \\
BJU jus mentimun post-test & 8 & 0.695 \\
\hline
\end{tabular}

Pada Tabel 3, jus mentimun menghasilkan taraf signifkansi pre-test 0.506 dan post-test sebesar 0.585. Seluruh variabel menunjukkan taraf signifikansi lebih dari nilai Alpha ( $>00.05)$. Dapat disimpulkan bahwa H0 diterima dan seluruh data berdistribusi homogen.

Tabel 3. Uji Homogenitas Jus Mentimum

\begin{tabular}{lll}
\hline Variabel & N & Sig \\
\hline Pre_test_Mentimun & 8 & 0.506 \\
Post_test_Mentimun & 8 & 0.585 \\
\hline
\end{tabular}

Pada Tabel 4, ditampilkan bahwa nilai signifikansi sebesar $\mathrm{p}=0,83$. Taraf signifikansi lebih dari nilai Alpha (p>0.05) dan dapat ditarik kesimpulan bahwa $\mathrm{H}_{0}$ diterima dan dapat disimpulkan bahwa tidak ada perbedaan rata-rata BJU sebelum dan sesudah diberi dehydrating exercise test. Hal ini menunjukkan bahwa adanya pengaruh jus mentimun dalam mengurangi potensi terjadinya dehidrasi.
Tabel 4. Uji Hipotesis Jus Menimun

\begin{tabular}{lllll}
\hline Variabel & $\mathrm{N}$ & Std.Dev & Sig & Kesimpulan \\
\hline BJU & 8 & 0.001923 & 0.83 & $\begin{array}{l}\text { Tidak } \\
\text { signifikan }\end{array}$ \\
\hline
\end{tabular}

Temuan Minuman Isotonik

Pada Gambar 2, variabel pre-test minuman isotonik dengan standar devisiasi 0,00372 memiliki nilai rata-rata sebesar 1,01012 dengan nilai maksimum 1,018 dan nilai minimum 1,005. Variabel post-test minuman isotonik dengan standar devisiasi 0,003139 memiliki nilai ratarata sebesar 1,01113 dengan nilai maksimum 1,018 dan nilai minimum 1,008.

Tabel 5. Uji Normalitas Minuman Isotonik

\begin{tabular}{lll}
\hline Variabel & N & Sig \\
\hline BJU minuman isotonik pre-test & 8 & 0.179 \\
BJU minuman isotonik post-test & 8 & 0.070 \\
\hline
\end{tabular}

Pada hasil dari uji normalitas Shapiro Wilk minuman isotonik yang terdapat pada Tabel 5 didapatkan taraf signifikansi dari data BJU minuman isotonik pre-test sebesar 0.179 dan BJU minuman isotonik post-test sebesar 0.070. Seluruh variabel menunjukkan taraf signifikansi lebih dari nilai Alpha ( $>00,05)$. Dapat ditarik kesimpulan bahwa $\mathrm{H}_{0}$ diterima dan disimpulkan data normal.

Hasil dari uji homogenitas yang ditampilkan pada Tabel 6, menghasilkan taraf signifikansi variabel BJU pre-test Pocari sebesar 0.376 sedangkan BJU post-test Pocari sebesar 0.214. Nilai signifikansi pada variabel tersebut lebih 
dari nilai alpha ( $>>0.05)$. Dapat disimpulkan bahwa $\mathrm{H}_{0}$ diterima dan seluruh data homogen.

Tabel 6. Uji Homogenitas Minuman Isotonik

\begin{tabular}{lll}
\hline Variabel & N & Sig \\
\hline BJU minuman isotonik pre-test & 8 & 0.376 \\
BJU minuman isotonik post-test & 8 & 0.214 \\
\hline
\end{tabular}

Dari hasil uji hipotesis didapatkan nilai signifikansi sebesar $p=1,52$. (Tabel 7). Taraf signifikansi lebih dari nilai alpha $(p>0,05)$ dan dapat ditarik kesimpulan bahwa $\mathrm{H}_{0}$ diterima dan dapat disimpulkan bahwa tidak ada perbedaan rata-rata BJU sebelum dan sesudah diberi dehydrating exercise test. Hal ini menunjukkan bahwa adanya pengaruh minuman isotonik dalam mengurangi potensi terjadinya dehidrasi.

Tabel 7. Uji Hipotesis Minuman Isotonik Terhadap tingkat Dehidrasi

\begin{tabular}{llll}
\hline Variabel & $\mathrm{N}$ & Sig & Kesimpulan \\
\hline BJU & 8 & 1.52 & Tidak signifikan \\
\hline
\end{tabular}

Temuan Perbandingan Jus Mentimun dan Minuman Isotonik Terhadap Tingkat Dehidrasi

Pada Tabel 8, setelah diuji hipotesis didapatkan bahwa, nilai signifikansi diperoleh sebesar 0.696, lebih besar dari nilai Alpha ( $>>0,05)$ dan dapat disimpulkan bahwa $\mathrm{H}_{0}$ diterima dan dapat disimpukan bahwa tidak ada perbedaan pemberian mentimun dan minuman isotonik terhadap tingkat dehidrasi.

Tabel 8. Perbandingan Jus Mentimun dan Minuman Isotonik Terhadap Tingkat Dehidrasi

\begin{tabular}{llll}
\hline Variabel & N & Sig & Kesimpulan \\
\hline Gain BJU & 8 & 0.696 & Tidak Signifikan \\
\hline
\end{tabular}

Temuan Penilaian Subjektif Jus Mentimun dan Minuman Isotonik Terhadap Tingkat Dehidrasi

Pada Gambar 3, diperlihatkan bahwa penilaian subjektif Thirst minuman isotonik memiliki nilai maksimum sebesar 5.00, nilai minimum sebesar 2.00, dan standar deviasi 0.99103, sedangkan penilaian subjektif Thirst jus mentimun memiliki nilai maksimum 4.00, nilai minimum 2.00, dan standar deviasi 0.7071. Peni-laian subjektif Bloatedness minuman isotonik memiliki nilai maksimum 5.00, nilai minuman 2.00, standar deviasi 1.06066, sedangkan penilai-an subjektif Bloatedness jus mentimun memiliki nilai maksimum 4.00, nilai minimum 2.00, dan stadar deviasi 0.83452. Peniliaian subjektif Refreshed minuman isotonik memiliki nilai maksimum 5.00, nilai minimum 3.00, standar deviasi
0.83452 , sedangkan pada peniliaian subjektif Refreshed jus mentimun memiliki nilai minimum 3.00, nilai maksimum sebesar 5.00, dan standar deviasi 0.75592. Penilaian subjektif Stomach upset minuman isotonik memiliki nilai maksimum 5.00, nilai minimum 2.00, standar deviasi 1,30247. Sedangkan pada peniliaian subjektif Stomach upset jus mentimun memiliki nilai minimum 2.00, nilai maksimum 4.00 dengan standar deviasi 0.7071. Peniliaian subjektif Tiredness minuman isotonik memiliki nilai maksimum 5.00, nilai minimum 3.00, standar deviasi 0,7559 . Sedangkan pada peniliaian subjektif Tiredness jus mentimun memiliki nilai minimum 3.00, nilai maksimum 5.00, dengan standar deviasi 0.7071 .

Pada Tabel 9 diperlihatkan bahwa, variabel penilaian subjektif Thirst minuman isotonik memiliki taraf signifikansi sebesar 0.156 dan pada jus mentimum memiliki taraf signifikansi sebesar 0.56. Variabel penilaian subjektif Bloatedness minuman isotonik memiliki taraf signifikansi sebesar 0.366 dan pada jus mentimum memiliki taraf signifikansi sebesar 0.67. Variabel penilaian subjektif Refreshed minuman isotonik memiliki taraf signifikansi sebesar 0.67 dan pada jus mentimum memiliki taraf signifikansi sebesar 0.93. Variabel penilaian subjektif Stomach upset minuman isotonik memiliki taraf signifikansi sebesar 0.088 dan pada jus mentimum memiliki taraf signifikansi sebesar 0.056. Variabel penilaian subjektif Tiredness minuman isotonik memiliki taraf signifikansi sebesar 0.093 dan pada jus mentimum memiliki taraf signifikansi sebesar 0.056 . Seluruh variabel dalam setiap kelompoknya menunjukkan taraf signifikansi lebih dari nilai alpha $(p>0,05)$. Dapat ditarik kesimpulan bahwa H0 diterima dan disimpulkan data normal.

Pada tabel 10, variabel penilaian subjektif Refreshed minuman isotonik memiliki taraf signifikansi sebesar 0.506 dan pada jus mentimum memiliki taraf signifikansi sebesar 1.000. Variabel penilaian subjektif Stomach upset minuman isotonik memiliki taraf signifikansi sebesar 0.506 dan pada jus mentimum memiliki taraf signifikansi sebesar 1.000. Variabel penilaian subjektif Tiredness minuman isotonik memiliki taraf signifikansi sebesar 1.000 dan pada jus mentimum memiliki taraf signifikansi sebesar 1.000. Seluruh variabel menunjukkan taraf signifikansi lebih dari nilai alpha ( $>0.05)$. Dapat disimpulkan bahwa H0 diterima dan seluruh data homogen 
Jurnal Keolahragaan 7 (1), 2019 - 71

Rizki Yudha Pratama, Imas Damayanti, Yati Ruhayati

Tabel 9. Uji Normalitas Penilaian Subjek

\begin{tabular}{lll}
\hline Variabel & N & Sig \\
\hline Penilaian subjektif Thirst minuman isotonik & 8 & 0.156 \\
Penilaian subjektif Thirst jus mentimun & 8 & 0.56 \\
Penilaian subjektif Bloatedness minuman isotonik & 8 & 0.356 \\
Penilaian subjektif Bloatedness jus mentimun & 8 & 0.67 \\
Penilaian subjektif Refreshed minuman isotonik & 8 & 0.67 \\
Peniliain subjektif Refreshed jus mentimun & 8 & 0.93 \\
Penilaian subjektif Stomach upset minuman isotonik & 8 & 0.88 \\
Penilaian subjektif Stomach upset jus mentimun & 8 & 0.56 \\
Peniliaian subjektif Tiredness minuman isotonik & 8 & 0.93 \\
Penilaian subjektif Tiredness jus mentimun & 8 & 0.56 \\
\hline
\end{tabular}

Tabel 10. Uji Homogenitas Penilaian Subjek

\begin{tabular}{lll}
\hline Variabel & N & Sig \\
\hline Penilaian subjektif Thirst minuman Isotonik & 8 & 0.458 \\
Penilaian subjektif Thirst jus mentimun & 8 & 0.506 \\
Penilaian subjektif Bloatedness minuman isotonik & 8 & 0.506 \\
Penilaian subjektif Bloatedness jus mentimun & 8 & 0.506 \\
Penilaian subjektif Refreshed minuman isotonik & 8 & 1.000 \\
Peniliain subjektif Refreshed jus mentimun & 8 & 1.000 \\
Penilaian subjektif Stomach upset minuman isotonik & 8 & 0.506 \\
Penilaian subjektif Stomach upset jus mentimun & 8 & 1.000 \\
Peniliaian subjektif Tiredness minuman isotonik & 8 & 1.000 \\
Penilaian subjektif Tiredness jus mentimun & 8 & 1.000 \\
\hline
\end{tabular}

Tabel 11. Perbandingan Penilaian Subjektif Jus Mentimun dan Minuman Isotonik

\begin{tabular}{llll}
\hline Variabel & N & Sig & Kesimpulan \\
\hline Thirst & 8 & 0.398 & Tidak Signifikan \\
Bloatedness & 8 & 0.609 & Tidak Signifikan \\
Refreshed & 8 & 0.758 & Tidak Signifikan \\
Stomach upset & 8 & 0.486 & Tidak Signifikan \\
Tiredness & 8 & 0.506 & Tidak Signifikan \\
\hline
\end{tabular}

Pada Tabel 11 menunjukkan nilai signifikansi sebesar Thirst 0.398, Bloatedness 0.609, Refreshed 0.758, Stomach upset 0.486, dan Tiredness 0.683. Semua variabel tersebut memiliki signifikasi lebih besar dari nilai alpha $(p>0,05)$ dan dapat disimpulkan bahwa tidak ada perbeda-an yang signifikan pada penilaian subjektif antara minuman isotonik dan jus mentimun.

\section{Pembahasan}

Penelitian ini dilakukan untuk melihat perbedaan jus mentimun dan minuman isotonik terhadap tingkat dehidrasi. Penelitian ini mencoba untuk melihat efek dari pemberian konsumsi minuman isotonik dan jus mentimun terhadap tingkat dehidrasi. Sangat penting menjaga tubuh agar tetap terhidrasi karena menurut Murray (2007) dehidrasi pada saat olahraga menyebabkan penurunan konsentrasi,kecepatan reaksi, meningkatnya suhu tubuh dan terjadinya penghambatan laju energi. Bahkan pada 9\% kehilangan berat badan akibat dehidrasi dapat mengakibatkan kegagalan ginjal (Santoso et al. , 2011). Ada beberapa faktor yang mempengaruhi dehidrasi yaitu status gizi, jenis kelamin, suhu, aktivitas fisik, konsumsi air, pengetahuan, dan usia. Aktivitas fisik dapat mempengaruhi terjadinya dehidrasi. Menurut penelitian Luettgen et al. (2012) pada olahraga Zumba selama 39 menit atau selama satu kelas Zumba, kalori yang terbakar sekitar 369 kalori atau sekitar 9,5 kkal per menit (lebih besar bila dibandingkan dengan bersepeda maupun lari). Sehingga dengan olahraga Zumba selama 1 jam dan dengan intensitas Zumba yang sedang ke tinggi dapat memacu terjadinya dehidrasi. Bahkan, Stalker (2018) mengungkapkan bahwa jika intensitas dan durasi latihan semakin tinggi maka energi dan kalori yang keluar semakin besar. Selain aktivitas fisik, terdapat faktor lain yang mempengaruhi dehidrasi yaitu konsumsi air. Konsumsi air dari sumber makanan dan minuman sangat dibutuhkan oleh tubuh untuk proses sirkulasi dalam 
tubuh untuk transport sel dan pengatur suhu tubuh, apabila cairan yang keluar tidak digantikan dengan cairan jumlah cairan yang masuk ketubuh maka akan mengakibatkan sel-sel dalam tubuh kehilangan air, hal inilah yang akan menyebabkan terjadinya dehidrasi. Berbanding lurus dengan semakin banyak energi dan kalori dikeluarkan makan individu akan semakin membutuhkan cairan dan elektrolit. Aktivitas yang tinggi maupun rendah dapat berpeluang terjadinya dehidrasi.

\section{Pembahasan Temuan Penelitian 1}

Hasil temuan penelitian menunjukkan perubahan rata-rata nilai berat jenis urin pada treatment jus mentimun sebesar $0.001500 \mathrm{~g} / \mathrm{dl}$. Secara perhitungan statistik jus mentimun menunjukkan tidak adanya perbedaan rata-rata yang signifikan $(p>0,05)$ antara sebelum dan sesudah treatment. Mentimun merupakan buah dengan kadar air sangat banyak di dalamnya. Menurut Maheshwari et al. (2014) mengemukakan bahwa timun mempunyai elektrolit penting dan mengembalikan tingkat hidrasi. Mentimun juga mengandung kadar air yang sangat banyak sekitar 96\%. Selain berasal dari bahan alami dan tidak menggunakan pengawet, jus mentimun juga mempunyai banyak manfaat yang tidak dimiliki oleh minuman isotonik. Mentimun memliki manfaat yang sangat banyak sekali. Ada beberapa manfaat mentimun menurut Maheshwari et al. (2014) yaitu selain dapat mengatasi dehidrasi, mentimun juga dapat membantu menjaga tekanan darah karena banyak mengandung $\mathrm{K}, \mathrm{Mg}$, dan serat yang sangat membantu menjaga tekanan darah. Mentimun juga dapat mengatasi dehidrasi karena mengandung 96\% air yang bernutrisi lebih dari air biasanya, yang mampu menjaga agar tubuh terhidrasi dengan baik. Mentimun juga mempunyai kandungan silika yang dapat memperbaiki kesehatan sendi dengan memperkuat jaringan ikat.

Pembahasan Temuan Penelitian 2

Hasil temuan penelitian menunjukkan perubahan rata-rata nilai berat jenis urin pada treatment minuman isotonik sebesar 0.001006 $\mathrm{g} / \mathrm{dl}$. Secara perhitungan statistik minuman isotonik menunjukkan tidak adanya perbedaan ratarata secara signifikan $(p>0,05)$ antara sebelum dan sesudah treatment. Minuman isotonik sering juga disebut sebagai sport drinks, carbohydrateelectrolite atau electrolite replacement drinks yang pada umumnya mengandung air, karbohidrat dan sejumlah kecil mineral (elektrolit) seperti natrium, kalium, klorida dan fosfat ( $\mathrm{R}$. Murray \& Stofan, 2000). Penelitian mengenai sport drink sudah dilakukan sebelumnya oleh Kalman et al. (2012), membuktikan bahwa adanya pengaruh pada pemberian minuman isotonik terhadap tingkat dehidrasi. Menurut Murray \& Stofan (2010), minuman isotonik di ciptakan untuk memberikan manfaat yang berarti dalam seluruh keadaan, seperti merangsang penyerapan cairan dengan cepat, asupan karbohidrat secara instan, meningkatkan respon fisiologis, dan mempercepat rehidrasi. Jadi dapat disimpulkan bahwa minuman isotonik dapat mengurangi potensi terjadinya dehidrasi.

\section{Pembahasan Temuan Penelitian 3}

Nilai signifikansi antara treatment jus mentimun dan minuman isotonik diperoleh sebesar $0.696(p>0,05)$. Hasil itu diraih dari hasil perlakuan yang diberikan kepada sampel yakni pemberian jus mentimun dan minuman isotonik sebanyak $250 \mathrm{ml}$ sebanyak 2 kali pemberian dengan waktu latihan selama 1 jam pada periode yang berbeda dimana setiap periode berdurasi 3 hari. Berdasarkan hasil tersebut, diketahui bahwa tidak terdapat perbedaan rata-rata nilai berat jenis urin secara signifikan. Hal ini membuktikan bahwa jus mentimun dapat mencegah terjadinya dehidrasi sama bagusnya dengan minuman isotonik.

\section{Pembahasan Temuan Penelitian 4}

Nilai signifikansi antara penilaian subjektif jus mentimun dan minuman isotonik sebesar Thirst 0.398, Bloatedness 0.609, Refreshed 0.758, Stomach upset 0.486, dan Tiredness 0.683 . Semua variabel diatas memiliki signifikasi lebih besar dari nilai alpha $(p>0,05)$ dan disimpulkan bahwa tidak terdapat perbedaan yang signifikan pada penilaian subjektif antara minuman isotonik dan jus mentimun. Ini menunjukkan bahwa jus mentimun bisa menjadi pilihan minuman olahraga untuk mengantikan minuman isotonik karena dari penilaian subjektif tidak tedapat perbedaan yang signifikan.

\section{SIMPULAN}

Berdasarkan data yang sudah dianalisis dapat disimpulkan bahwa mentimun dapat menjadi pilihan minuman olahraga untuk mengatasi dehidrasi. Diketahui juga dari penelitian ini jus mentimun mempunyai manfaat yang sama baiknya dengan minuman isotonik tetapi jus mentimun mempunyai kelebihan yang tidak dimiliki oleh minuman isotonik. Selain dibuktikan dengan 
hasil dari berat jenis urin, jus mentimun juga sama baiknya dengan minuman isotonik dalam hal pandangan subjektif. Kesimpulan dari penelitian ini adalah jus mentimun bisa menggantikan minuman isotonik sebagai minuman olahraga untuk mencegah terjadinya dehidrasi

\section{DAFTAR PUSTAKA}

Adan, A., \& Adan, A. (2012). Cognitive performance and dehydration. Journal of the American College of Nutrition, 26(5), $549 \mathrm{~S}$ $554 \mathrm{~S}$. https://doi.org/10.1080/07315724.2012.10 720011

Amin, A. R. (2015). Mengenal budidaya mentimun melalui pemanfaatan media informasi. JUPITER, XIV(1), 66-71. https://doi.org/1693-5535

Dwita, L. P., Amalia, L., Iwo, M. I., \& Bahri, S. (2015). Pengaruh rehidrasi menggunakan air kelapa (cocos nucifera 1) terhadap stamina atlet dayung. Farmasains, 2(5), 229-233.

Galemore, C. A. (2011). Sports drinks and energy drinks for children and adolescents-are they appropriate? PEDIATRICS, 26(5), 320-321. https://doi.org/10.1177/1942602x1141731 0

Irawan, M. A. (2007). Nutrition, energy, and sport performance. Sport Science Brief, 1(4), 1-13.

Kalman, D. S., Feldman, S., Krieger, D. R., \& Bloomer, R. J. (2012). Comparison of coconut water and a carbohydrateelectrolyte sport drink on measures of hydration and physical performance in exercise-trained men. Journal of the International Society of Sports Nutrition, 9(1), 1-10. https://doi.org/10.1186/15502783-9-1

Koswara, S. (2009). Minuman isotonik. Semarang: Universitas Muhammadiyah Semarang.

Luettgen, M., Foster, C., Doberstein, S., Mikat, R., \& Porcari, J. (2012). Zumba: Is the "fitness-party" a good workout? Journal of Sports Science and Medicine, 11, 357358. Retrieved from https://www.jssm.org/hf.php?id=jssm-11357.xml

Maheshwari, R. K., Mohan, L., Malhotra, J., Updhuay, B., \& Rani, B. (2014). Invigorating efficacy of cucumis sativas for healthcare \& radiance. International Journal of Chemistry and Pharmaceutical Sciences, 2(3), 737-744. https://doi.org/2321-3132

Minton, D. M., O'Neal, E. K., \& TorresMcGehee, T. M. (2014). Agreement of urine specific gravity measurements between manual and digital refractometers. Journal of Athletic Training, 50(1), 59-64. https://doi.org/10.4085/1062-605049.3.47

Murray, B. (2007). Hydration and physical performance. Journal of the American College of Nutrition, 26(5), 542S - 548S. https://doi.org/10.1080/07315724.2007.10 719656

Murray, R., \& Stofan, J. (2000). Formulating carbohydrate-electrolyte drinks for optimal efficacy. In Sports Drinks: Basic Science and Practical Aspects (pp. 197223). Boca Raton. https://doi.org/10.1201/9781420037180.c h8

Santoso, B. I., Hardinsyah, S. P., \& Pardede, S. O. (2011). Air bagi kesehatan. Jakarta: Centra Communications.

Stalker, T. (2018). Factors affecting hydration. CeraSport Hydration, 8(1), 1-4.

University of Bristol. (2017). Urinalysis: specific gravity. University of Bristol.

Zanzer, Y. C. (2011). Teh hijau dalam mengontrol level glukosa plasma darah post-prandial. Gizi Masyarakat. Institut Pertanian Bogor. 